\title{
Storytelling agents: why narrative rather than mental time travel is fundamental
}

\author{
Rosa $\operatorname{Hardt}^{1}$ (D)
}

Published online: 24 August 2017

(C) The Author(s) 2017. This article is an open access publication

\begin{abstract}
I propose that we can explain the contribution of mental time travel to agency through understanding it as a specific instance of our more general capacity for narrative understanding. Narrative understanding involves the experience of a pre-reflective and embodied sense of self, which co-emerges with our emotional involvement with a sequence of events (Velleman 2003). Narrative understanding of a sequence of events also requires a 'recombinable system', that is, the ability to combine parts to make myriad sequences. Mental time travel shares these two characteristics: it involves an embodied sense of self and the ability to create novel scenarios. What is unique about mental time travel is that it is a story explicitly about our selves, and it involves metarepresentation. Agency is enabled by narrative understanding when we are able to put our current situation into a larger narrative context, whereby some possible actions, but not others, make sense. However, new features of agency are enabled when we understand stories that are explicitly about our selves: we gain the ability to plan and act on plans.
\end{abstract}

Keywords Narrative $\cdot$ Mental time travel $\cdot$ Agency $\cdot$ Emotion $\cdot$ Metarepresentation

\section{Introduction}

What makes agency possible? The ability to understand narratives and the ability to mentally time travel have both been put forward as ways to understand how it is possible for a creature to act for reasons, where acting for reasons is a way to characterise agency. I am going to argue that, once we have a more precise idea of what we mean by narrative understanding, there are good reasons to think that mental time travel is a type of narrative understanding. Once we understand this, we can see how different types of narrative understanding make different aspects of agency possible.

Rosa Hardt

rosa.e.hardt@gmail.com

1 University of Edinburgh, Edinburgh, UK 
Both narrative understanding and mental time travel (the capacity to inhabit your past and possible future) have been put forward as central to our sense of self and our capacity to make and act on decisions (e.g. Velleman 2007; Dennett 1989; Gerrans and Kennett 2010). While psychological literature focuses on decision-making (Suddendorf and Corballis 2007; Kwan et al. 2012), in philosophy, these debates about narrative understanding and mental time travel centre on the idea of agency (Velleman 2007; Gerrans and Kennett 2010, 2017; Kennett and Matthews 2008). The idea that agency is the capacity to act for reasons, and the idea of an agent as a creature able to plan and act on plans, are often associated (Bratman 2000; Korsgaard 1989), but need not be seen as synonymous.

While both narrative understanding and mental time travel have been put forward as capacities that make agency possible, I argue that it is narrative understanding that is fundamental to agency because mental time travel is just a special case of narrative understanding. Specifically, mental time travel is narrative understanding that is explicitly about one's self. Further, specifying the different ways that self is present in narrative understanding is important for characterising the different ways narrative understanding can contribute to agency.

The central observation that sets off this line of thought concerns the overlapping characteristics that mental time travel and narrative understanding share. Both share an experiential component. When we mentally time travel, we inhabit our past and potential future. And the understanding we gain from engaging with narratives is characterised by our ability to inhabit a sequence of events. I will explore this issue in section 3.2. Both experiential components, I suggest, are made possible by what Velleman (2003) calls 'an affective cadence'. We inhabit narratives, and our own past and possible futures, because their affective nature co-emerges with a sense of self. There is also a second commonality. And this is that both mental time travel and narrative understanding engage our ability to understand and recombine causal chains.

The central difference that I want to highlight - what makes narrative understanding a broader category than mental time travel - is that it need not be explicitly about our selves or our lives. We understand narratives, for example, when reading a novel, or watching a film, and maybe when listening to certain news items. Mental time travel, on the other hand, is explicitly about our own lives, and involves metarepresentation. ' 'Metarepresentation' is the ability to represent something as representational, such as when we think about our beliefs as beliefs. Nonetheless, given the phenomenology of narrative understanding, narrative understanding always contains an implicit sense of self, $^{2}$ and an implicit sense of what the narrative means to us. This implicit sense of self is present even when the narrative is not explicitly about our selves or our lives. Given this, the quality of mental time travel, as explicitly including a creature we take to be our selves, is a genre of narrative understanding. It is narrative understanding where we are explicitly aware that one of the creatures in the narrative is our selves.

\footnotetext{
${ }^{1}$ It may be that we need not define mental time travel as metarepresentational. However, psychologists have defined it this way (see Wheeler et al. 1997).

${ }^{2}$ It is possible to question whether metarepresentation can be implicit. I wish to bracket this question. Instead, what I am understanding as 'metarepresentation' is the explicit awareness of something as being representational.
} 
Further, I explain how it is possible for narrative understanding to contribute to our agency by incorporating a pre-reflective sense of self. Reflective awareness of our selves has often been thought to be crucial to agency (e.g. Velleman 1992; Bratman 2000), and so my account challenges this school of thought. Awareness of our selves as selves, in such theories that focus on the reflective self, enables us to have reasons for action. This is because we have reasons for action when we do what would make sense in light of who we are (Bratman 2000; Korsgaard 1989; Velleman 1992, 2007). In some theories, our self-understanding is pivotal to having reasons for actions when it helps us decide upon, and act on, long-term plans (Bratman 2000; Gerrans and Kennett 2010). Our long-term plans count as reasons for action because they enable our actions to be guided by our deliberation rather than our behaviour being caused by immediate stimuli (Gerrans and Kennett 2010).

As we shall see, these theories use the language of metarepresentation at times. It can seem natural to think of self-understanding as metarepresentational understanding; to think that to know who we are, to work out how we should act, and to make plans, we need to think of our mental states as representational states. Perhaps knowing myself involves knowing, for example, that I have the belief that Armageddon is here, and thinking about my feeling of anxiety as the feeling of anxiety. Or, perhaps, to plan where to go on holiday, I must consider my current beliefs and desires, and think about what I might desire and feel in the future. If I believe that in three months time I'll be exhausted, I should plan a relaxing holiday rather than an adventure.

We can mine this intuition that metarepresentation is important for agency a bit further. One theoretical reason behind our intuitive ideas about the importance of metarepresentation to agency could be that metarepresentation is necessary for the type of unity needed for agency. For Bratman (2000), human agency is a result of our plans and policies being used to decide what intentions we should currently act on. And it is because we can plan that our desires are subject to the types of norms distinctive to humans: norms of "consistency, coherence and stability" (2000, p. 42.).

In contrast to this view, I am claiming that we can have reasons for actions that make sense in light of who we are through narrative understanding, and before we use metarepresentation. If, as I will argue, all narrative understanding involves an emotional cadence that co-emerges with a pre-reflective sense of self, then the stories we understand express a sense of what they mean to us. This sense of the meaning of events, which is simultaneously a pre-reflective sense of self, provides the possibility of having reasons for actions. Narrative understanding, I suggest, enables agency through having the potential to be articulated, reflected on and changed.

To proceed, I want to start by outlining the two parallel debates. First, in section 2, I give an account of recent philosophical and psychological discussions concerning mental time travel. Then, in section 3.1, I explain the debate between philosophers concerning narrative understanding and its role, or lack of role, in selfhood and agency. In section 3.2, I examine how to best clarify the nature of narrative understanding. Next, in section 4, I explain how mental time travel can be explained through our capacity for narrative understanding, and I explain how narrative understanding makes agency possible.

Through this exploration of the relationship between narrative understanding and mental time travel, I come to a clearer and fuller picture of agency: one in which our capacity for agency is multifaceted, yet made possible by processes that are 
interestingly connected. I argue that narratively understood pasts and futures can provide us with reasons for actions in the present, without explicit notions of self. In contrast, to plan for the distal future, and to act on it, we need to have some explicit understanding of self, but that need not be metarepresentational.

\section{Mental time travel}

Much of the focus on mental time travel has been on its contribution to making and acting on decisions (e.g. Debus 2007; Gerrans and Kennett 2010; Suddendorf and Corballis 2007). There has also been some focus on metaphysical issues - whether forward and backward time travel are the same kind of process (Debus 2014) - as well as conceptual issues concerning the relationship between thinking about, and experiencing, the past (Debus 2013). These latter issues will be bracketed in this paper. It is the issue of making and acting on decisions that is of most relevance to concurrent debates about narrative. In what follows, I will be picking up on those features of mental time travel that I think can be made coherent by understanding it as a form of narrative understanding.

Suddendorf and Corballis (2007) developed their account of mental time travel to argue that its contribution to planning is its primary function. Further, episodic memory, as the re-experiencing of the past, is best understood as a form of mental time travel. Suddendorf \& Corballis write, "we argue that the primary role of mental time travel into the past is to provide raw material from which to construct and imagine possible futures" (p. 302). Episodic memory involves 'autonoetic' consciousness. Autonoetic consciousness involves representing, and becoming aware of, our subjective experiences through time (Wheeler et al. 1997). Episodic memory is characterised, as all mental time travel is, by being an experience of a particular event and situation. Suddendorf \& Corballis's claim, therefore, is that the primary function of the ability to recollect particular specific instances is that we have a collection of experiences that we can combine in various ways to form novel possible situations. For example, if I have a memory of getting into a conflict with one friend because I was insensitive when I explained why their actions made me angry, then, when considering how to communicate my current frustration with another friend, I can use my past experiences to imagine what the result would be if I didn't handle the situation sensitively with them.

Evolutionary psychology is the standpoint through which Suddendorf \& Corballis make the assessment that we should understand episodic memory - backward mental time travel - through how it contributes to our future behaviour. They argue that, "mental time travel provides increased behavioural flexibility to act in the present to increase future survival chances" (2007, p. 302.) because,

In allowing us to foresee unique events, mental time travel offers the ultimate step in adaptation to the future. Like human language, it is open-ended and generative, so there is no end to the number of potential future scenarios one might envisage. (ibid.)

The claim is that it is the flexibility of mental time travel - that it can provide us with guidance on situations that we have not ever experienced - that is so useful for 
supporting our decision-making about what goals to pursue and how to reach them. Furthermore, Suddendorf \& Corballis are observing that mental time travel involves, what I will call, a 'recombinable system', in that it allows us to put together parts in different ways to generate novel situations and scenarios. I will pick up on this later in my description of narrative understanding and its relationship to mental time travel. ${ }^{3}$

However, it is Gerrans and Kennett's (2010) analysis of the relationship between mental time travel and agency that makes a narrative understanding reading of mental time travel so appealing. This is because of the stress they put on the phenomenological aspect of mental time travel: for them, mental time travel is experienced through the feeling of being subjectively present in non-occurring events.

Gerrans \& Kennett are responding to a class of theories of moral judgements. Their central claim is that these theories make moral judgements 'synchronic' - either moral judgement relies on singular emotions felt in the present, or they rely on reasoning through premises. Yet, moral judgements, they point out, are the judgements of agents. And agents, they claim, are diachronic beings, in the sense that they can only come to judge, and act on those judgements, through their capacity to understand their lives through time (see, for example, Bratman 2000). This allows us to transcend the present moment, for our behaviour to be based on our plans and not just our current environment.

So, when we set ourselves goals, when we plan, when we are working out what matters to us, and when we act on all those things, Gerrans \& Kennett claim we use our knowledge of our autobiographies and the ability to mentally time travel. To explain why mental time travel is important, first we have to understand what Gerrans \& Kennett think is special about it. Gerrans \& Kennett describe the phenomenology of mental time travel as "essentially indexical" (p. 601) in that it involves the experience of inhabiting a sequence of events. By this, they mean that mental time travel includes the sense of our selves as being meaningfully related to the events in mental time travel. Mental time travel is "essentially indexical" because, when we engage in it, the sense of inhabiting a situation is a sense that both points to the self, and is the thing being pointed at.

For Gerrans \& Kennett, the combination of our autobiographical knowledge and our mental time travels enables us to think about what to do in terms of the kind of life we have led by giving our decisions context. More importantly, the experiential quality of mental time travel allows us to be sensitive to moral considerations and act on those considerations in the present and the future. Because, in mental time travel, we feel involved in non-actual situations, mental time travel makes manifest to us morally relevant aspects of our situation beyond what is currently before us. When we understand our autobiography subjectively, as well as the possible future consequences of different courses of action, Gerrans \& Kennett suggest that we become motivated to act in future-directed ways so that we are not just reacting to our current stimulus.

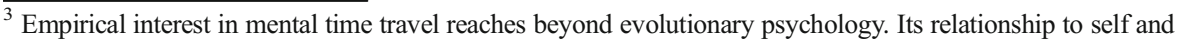
decision-making been explored by Markowitsch and Staniloiu (2011) and there is a burgeoning neuroscientific literature on the neural underpinning of episodic memory and mental time travel (e.g. Szpunar et al. 2007; Botzung et al. 2008; Viard et al. 2011.).
} 
As such, theories of moral judgement that leave out the contribution of our awareness, and knowledge, of our selves through time are mistaken. They cannot explain how we could be the type of things that can act morally when those moral issues transcend what can be ascertained solely on the basis of the situation we are currently faced with.

What is important, for my purposes, is Gerrans \& Kennett's suggestion that mental time travel is necessary for forming us as agents: creatures for whom reasons exist through time, who can act according to their values and long-term goals. Their argument for this is supported by co-occurring impairments of agency and mental time travel. In particular, they look at the cases of two people who have damage to their ventromedial prefrontal cortex (vmPFC), M.L. and EVR. M.L. can no longer reexperience episodes from his past. He acts irresponsibly, particularly in his role as a parent, and requires supervision. EVR has problems making decisions. He is constantly evaluating different options and finds it difficult to settle on one. To Gerrans \& Kennett, this suggests that,

What ventromedial patients lose is not just the ability to plan but the prerequisite sense of diachronic selfhood intimately connected with an autobiography with a distinctive emotional character... They have lost the sense of 'I' to whom the judgement is to be indexed so they literally don't know what to do. (p. 605.)

The claim here is that there is something about the experiential quality of mental time travel that anchors it to our sense of self. This experiential quality allows us to make judgements about the future, and enables us to act, now and in the future, on those judgements.

One last characteristic of mental time travel to pick up on is that it is always explicitly about our own lives - we represent our selves in it. And it is implied that its contribution to decision-making involves metarepresentation. Gerrans \& Kennett hint at this when they adopt Bratman's (2000) theory that agency requires us to "conceive of ourselves as agents who persist over time" (p. 601). This phrase suggests that we need to represent ourselves as teleological creatures - for that is what agents are defined as in this literature - in order to be teleological creatures. We find this idea hinted at, also, in the definition of 'autonoesis' above. By describing autonoesis as the representation of our subjective experience through time, what is suggested is that we are representing something representational. This feature, in the psychological literature, is part of the definition of mental time travel for reasons I mentioned earlier. It is natural to think of self-understanding as the ability to reflect on our representational states, such as our beliefs and desires.

So mental time travel has been put forward as involving a sense of being present in one's past or future. Another characteristic is its 'open-endedness': that it involves putting together parts and sequences to generate novel scenarios. These two aspects will be central to my argument that mental time travel is a type of narrative understanding. Finally, mental time travel is often described as a metarepresentational activity. This seems important for understanding why mental time travel is related to self-understanding, a claim that I will question. Now I turn to narrative understanding and its relationship to making and acting on decisions. 


\section{Narrative understanding}

\subsection{Narrative understanding, self \& agency}

Narrative understanding has been put forward as an ability that allows us to contextualise our own lives. And, like mental time travel, this has been argued to be important for selfhood and agency. Furthermore, it has been argued that narrative understanding enables action by integrating the self.

For Dennett, selves are the "center of narrative gravity" (1992, p. 103). We tell stories to constitute our selves, but these selves are abstract entities and, in some sense, do not actually exist. Like the centre of gravity, selves are abstractions that do not refer to a thing in the world in the sense that they do not have properties beyond what they are theorised to have: what we can hold to be true about selves does not come apart from acts of interpretation. Knowing our own selves involves understanding stories we tell through self-interpretation. For example, we can only decide whether to ascribe a belief to our self once we have interpreted our behaviour in a way that could be seen as in-line, or counter-to, that belief.

From Dennett's perspective, selves are woven together through telling stories about our past behaviour, enabling different bits of information to make a single, relatively unified, autobiography. This unification is important for enabling us to act (contra Velleman's 2005 reading of him). It gives us a way to work out what to do, because our autobiographical narrative about who we are can guide us.

Other philosophers make a similar proposal: the weaving together of our whole life is important for the type of integration needed for selfhood. For example, Atkins (2008) writes,

I have been claiming that the unity and integrity of one's identity is a selfconstitutive process of self-constancy - backward- and forward-looking processes in which I integrate my past, present, and anticipated attributes and experiences into chronological order. (p. 91-2)

Others have argued that an overarching autobiography is important for agency, where to be an agent requires that we work out what we ought to do by deciding what would be the best way for our life story to continue. Kennett and Matthews (2008) favour a narrative theory of an agent's self where "an important source of normative reasons is to be found in considerations of what would constitute the best, or something approximating the best, continuation of a life story" (p. 213, emphasis added) (see also, Schechtman 2007).

Velleman, however, offers some important variations on this theme. On Velleman's account (2005), narrative theories of self can contribute to an explanation of agency but only when combined with the desire to be coherent. We tell narratives, like with Dennett's theory, in an attempt to give an explanation of our behaviour, which makes that behaviour coherent as the action of single self. But agency, for Velleman, cannot be explained just through the existence of a story itself, although a story is needed. Agency is explained through the desire to be rational: the desire to do what would make sense for us to do. Stories enable us to achieve this desire. We decide what we should do on the basis of what would be a coherent way for the story to continue. So, for Velleman, 
we can be rational if we tell stories about our lives, and act in light of those stories. Unlike Dennett and others, Velleman is not suggesting that all our actions depend on a continuation of one over-arching story. Instead, we can tell many short stories that we act out, which can be as short "as the eating of a meal, the answering of a phone, or every itch scratched" (2005, p. 222-223).

In this discussion we arrive at an alternative explanation of what conditions make agency possible. Agency depends on a unified self for which some reasons for actions make sense and others don't (Velleman 1992). A narrative capacity seems to help enable this. Whether our narrative capacities consist of considering our whole life, or even just a small action sequence, our narrative understanding helps us work out what to do by putting our action in a context where only some actions make sense.

Yet there is something unsatisfying about this notion of agency without further conditions. There is a reason why, when talking about the relationship between narratives and agency, much of the discussion is framed in terms of 'autobiography' or 'diachronicity': making sense of one's life as a whole (Dennett 1989, 1992; Gerrans and Kennett 2010; Kennett and Matthews 2008). A whole life story fulfils an important function in providing reasons for actions that short stories about other things appear to miss.

An autobiographical understanding seems to create a mine-ness to our reasons: we don't just act on reason; we act for reasons that are ours, because we have the possibility of authoring the biographical story through which we act. In the process of creating stories about our selves, we reflect on our beliefs, motivations or previous actions, and try to tell a story that makes sense of these things. In this way, we can become authors of our own perspective. This means that we have responsibility over our actions; we are not (just) pushed about by the whims of the world. Short, worlddirected stories, however, do not appear to provide the right reflective environment to make our reasons attributable to us.

However, we can distinguish between the problem we are trying to address through considering our narrative capacities - which is what enables us to have reasons for doing something - and the particular way that people use narrative capacities help achieve this possibility. What I want to argue later is that it is enough that we could, if we wanted to, reflect on our narrative understanding, for us to have authorship over the narratives that guide us. Further, I will argue that the requirement that reflection be explicitly about our lives or our mental states does not necessarily follow from the requirement to have some sort of reflective capacity. That is, narratives are relevant to decision-making and agency even when they are not explicitly about our selves or our beliefs and desires. This conclusion comes about through a closer look at what is meant by 'narrative understanding', our task in section 3.2. below.

A prominent counter to theories of narrative self comes from Galen Strawson (2004). Strawson's reason for his assertion that narratives are not important for our selfhood is twofold. The first is that there appears to be people who are Episodic and rarely engage in Narrativity, including himself. Since he takes people who don't engage in Narrativity to have selves, Narrativity cannot be necessary for selfhood. We will unpack what Strawson means by this shortly. The second is that it seems that engaging in narrative is more likely to distort, and so undermine, our selves than to construct our selves, because when we make our lives into a story, we can smooth over inconsistencies, and find connections where there are none (2004, p. 447). This makes our narratives about our lives false representation of who we are. 
Strawson claims that it is simply false that our sense of self is narratively structured. He divides people into 'Diachronics' and 'Episodics'. 'Diachronics' are people who understand themselves as a self who has existed in the distal past and will exist for some time to come. Others, he argues, like himself, are 'Episodics'. For these people, "one does not figure oneself, considered as a self, as something that was there in the (further) past and will be there in the (further) future" (p. 430). While Diachronics are prone to engage in what he calls Narrativity (although do not necessarily do so), Episodics rarely do. Narrativity, for Strawson is, the activity of,

relatively large-scale coherence-seeking, unity-seeking, pattern-seeking, or most generally ... form-finding tendency when it comes to one's apprehension of one's life, or relatively large scale parts of one's life. (p. 441).

It is this understanding of what Narrativity consists in that leads Strawson to worry about any selfhood formed through our narrative understanding being a false construction. If Narrativity consists in finding large-scale patterns in an effort to create unity, then a lot of the details, messiness, and idiosyncrasies that make people who they are get edited out. More than that, we may find patterns where there are none.

On the flip side, Strawson has an issue with the approach that Velleman takes to our narrative capacities, where a narrative may be really short and not at all to do with one's life as a whole, or large parts of one's life. If stories, as Velleman claims, can be about eating a meal, or scratching an itch, then that seems to be a trivial sense of narrative (p. 439). There doesn't seem to be anything importantly narrative about eating a meal, in the sense that we normally understanding narrative. What we need to understand to understand eating a meal just seems to involve understanding a (relatively short) sequence of events. Such a truncated and insignificant sequence of events seems far removed from the stories we tell about our selves, or even the stories we understand from watching TV or reading a book. ${ }^{4}$ We will return to this worry after I've explained narrative understanding more precisely.

\subsection{Explaining narrative understanding}

So, I've given a summary of the philosophical positions that have been taken on narrative understanding and its relationship to self and agency. But there is some disagreement about this, both about how narrative understanding relates to self and agency, and whether it does at all. I'm going to propose two characteristics of narrative understanding. This will help me reassess its relationship to agency and explain why I think mental time travel is a type of narrative understanding.

There are two central features of narrative understanding I want to draw out here. The first I develop from observations of Velleman (2003) and Goldie (2012). While Velleman argues that narratives are essentially embodied and affective, and Goldie that they are crucially perspectival, I argue that these features emerge together. The second feature of narrative understanding I want to draw out is that it involves the capacity to put together and recombine parts.

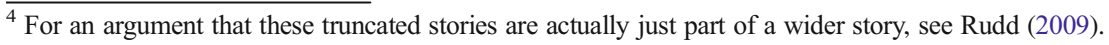


Velleman (2003) is interested in the difference between learning a non-narrative sequence of events and understanding a narrative. He thinks there must be a difference, because it seems that we gain a particular type of understanding when we understand a narrative that we do not gain from learning a non-narrative string of facts. We can think about the point of telling a fable, rather than just lecturing someone on morals. We tell stories in the form of fables so that people implicitly learn something about what is valuable and how we should live life. We can explain the same ideas in non-narrative form, but it seems we lose some type of understanding when we do so. There is a distinction, Velleman claims, between understanding a narrative and understanding a sequence of events that we need to explain.

So, what makes some types of understanding narrative understanding? Velleman (2003) suggests that when we understand a narrative we experience an emotional cadence. This emotional cadence discloses an embodied understanding of events to us because the cadence we experience when engaging with a narrative reproduces emotional patterns stored in "experiential, proprioceptive and kinaesthetic memory" (2003, p. 19). Understanding a narrative, for Velleman, replicates the experiential patterns that we go through in life, enabling us to relate narrative events to our lived experience. We understand the plight of the hero faced with a violent enemy through the fear produced that replicates our own experience of being intimidated.

For Velleman, these emotions enable us to both understand the events as they happen, and to understand what the narrative, as a whole, means to us. As we understand the unravelling of narrative events, our emotional engagement expresses a sense of a situation and how it relates to previous or future situations. For instance, Velleman (2003) suggests that grief, because of its capacity to register that we have lost something we value, points backwards through implying there was something to value that could be lost. That is, our emotional journey is also a sense-making journey, and emotions situate us not just in relation to the current event being depicted, but also in relation to past and future events. And, as Velleman talks of emotions as embodied reactions that register the sense of our situation, he understands emotions as 'embodied appraisals' (Prinz 2004) of some kind. In particular, this sense of the situation is relational: it expresses the way the situation relates to us. Grief is the experience that something we value has been lost.

Velleman also thinks that the emotion we are left with at the end of a narrative expresses an understanding of those events as whole by encapsulating the sense expressed in the previous emotions. So, we are left with an embodied sense of what the entire story means. Narrative understanding therefore comes with a sense of coherence enabled by our emotions.

Goldie's (2012) observation that what is special about narrative understanding is its perspectival character can be seen as related to Velleman's suggestion. Goldie comments that the,

Shaping, organising, and colouring [of the narrative] is informed by something that is at the heart of my account of narrative: the narrator's perspective or point of view from which the events are narrated (2012, p. 11).

For Goldie, telling or understanding a story may also involve a perspective internal to events, that is, the sense of being a character in a scene. But this feature, for Goldie, is optional. 
On the other hand, the external perspective is necessary for our understanding to be narrative, for Goldie, because it provides "the three characteristics of narrative: coherence, meaning, and evaluative and emotional import" (2012, p. 40). Rather than perspective providing evaluative and emotional import, however, we can think of perspective as emerging with evaluative and emotional import (for a similar idea see Ahmed 2004). That is, the former does not lead to the latter, but they are aspects of the same phenomenon.

This becomes easier to see when we think about the implications of Velleman's account of narrative understanding. Our emotional engagement with narratives, if we understand it as embodied sense-making, is already perspectival. That emotion, for Velleman, is "experiential, proprioceptive and kinaesthetic" and evaluative makes it perspectival both in the sense that it anchors us to a location through which we understand the world, and in the sense that a perspective on something is an evaluation of what it means to us. In this light, the emotional cadence we experience during engaging with narrative is a perspective on the events as they happen, and the final emotion we are left with at the end of a narrative is a perspective on the story as a whole.

It should be noted that Velleman himself does not understand narrative understanding as perspectival. Instead, I am suggesting that we ought to see his description of emotion as conveying a located sense of what a situation means for us, as a way of understanding what it is to have a perspective.

However, there is another major feature of narrative understanding that is part of this capacity but not unique to it. And that is that it uses a recombinable system through which it becomes possible to think through a sequence of events. Further, a recombinable system enables us to think through events in combinations that are potentially open-ended. So there are myriad stories that we tell and understand, and they work, partly, by stringing together chains of cause and consequence in various ways, or organising other types of information into coherent wholes. ${ }^{5}$ That is, narrative understanding depends on our capacity for using a recombinable system.

Such a recombinable system enables us to synthesise information in a way that makes sense. We see this in detective novels, where 'the big reveal' ties together various events and clues, or any story that has a twist. We can understand the twist to work precisely because we have relied on certain expectations about what is happening, or about to happen. But, in light of novel information, we are led to reconsider and reorganise our understanding of the causal chains between events and actors. Our surprise when the assumptions about how things are linked together in a narrative are overturned, such as in 'big reveals' and twists, exposes that we have implicit commitments to how events are connected.

However, for banal and more easily tractable examples, it is useful to think about media narratives. Such narratives involve the kind of emotional cadence talked about above. But they also involve background assumptions about how people and events are connected that enable the story to be coherent. Think about the story of the unemployed person who scrounges off the state. The story involves a couple of assumptions about

\footnotetext{
${ }^{5}$ See Ricoeur (1980) on the relationship between narrative and chronological understanding, for a similar point about narratives having, what Ricoeur calls, "a configurational dimension", as well as an "episodic dimension” (p.178).
} 
the connections between characters and events that enable it to make sense, even if we do not take the argument as true because we reject the premises. In this story, those who are unemployed and receiving support from the state do so because they are lazy and, if we were to remove the state support, then they would get a job. Their dependence on the state is a choice, in that they would have a job if they chose to. To understand this story, we must understand these connections even if we question the truth of the content. So there are two ways of characterising narrative understanding: its emotional cadence and the understanding of interlinked elements that make sense together.

Now I've explained what I take to characterise narrative understanding I can also respond to Strawson's worry that some descriptions of narrative understanding are trivial, if they do not involve finding large-scale coherences in our life. This is a problem for Strawson, because narrative understanding seems ubiquitous if we do not have such a definition of Narrativity. But the worry of ubiquity could only lead to a charge of triviality if one could not characterise narrative understanding in a way that was interesting. For example, it would only be trivial to say that everything is made of atoms if we could not say much about what an atom is. Similarly, we can give a substantive account of narrative understanding. Now we can see that we can explain narrative understanding through its emotional structure, which is also a recombinable structure.

This makes narrative understanding diachronic in one way: it is an emotional understanding of events through time (i.e. an emotional cadence), and this understanding is what its emotional recombinable structure enables. It is not necessarily diachronic in the sense that 'diachronicity' is often used. That is, it doesn't necessarily involve explicitly understanding oneself through time or planning.

The question is then: does our understanding of itch-scratching or meal-eating have these characteristics? This depends partly on how prevalent we think emotions are in our engagement with the world.

If, like myself, you think that all understanding is emotional, you can still admit that it might vary in intensity. Therefore, our understanding may be more or less narrative. For instance, if the itch-scratching occurs in a context that engages our emotions more, its narrative nature becomes more obvious. Here's another description of a sequence of events: Alysha had a really itchy nose, but she'd broken both her hands, and they were in casts. Frustrated, she started rubbing her nose against a rough wall but, when she did this, her older brother walked into the room, giving him the opportunity to tease her mercilessly. Our emotional engagement is more intense here, making our understanding of events more narrative.

If you think one can understand a sequence of events such as itch-scratching or meal-eating without any emotional engagement, then this makes the case even clearer. Understanding these events is not understanding a story when the necessary emotional component is missing. We might apply this to the example above: if one thinks that it is possible to understand something with no emotional engagement, then the case of the generic scrounger may not be a narrative until we flesh it out with more personality. Understanding the events involved in generic state-scrounging, in this case, is just understanding a sequence of events. On this more restricted view of emotions, once the sequence of events we are being told about is no longer about a generic scrounger but the feckless and selfish Mrs. Smith, who uses her benefits to buy champagne, then we start understanding the events narratively. 
On top of this, we can consider the second element of narrative understanding: it involves the combination of various elements into a coherent whole. Itch-scratching and meal-eating have relatively few parts to their sequences. Understanding these sequences may be understanding a story, but they are pretty unsatisfying stories to understand. Another feature of the story about Alysha is that more parts are coming together to form a whole, and so it is a more paradigmatic example of a story.

One response here is that when I vary the degree to which a sequence of events is understood narratively, what I am really varying is the amount of detail, rather than emotional intensity. ${ }^{6}$ As long as we increase the detail of a sequence of events, we make it more narrative. For example: Alysha scratched her nose with the index finger of her left hand, then her brother came into the living room where she was sat watching TV, followed by her mother, followed by her father holding a cup of tea.

The details of this sequence are not conducive to rich narrative experience, unlike the details that led to Alysha's earlier humiliation. This reduced narrative experience is explained by the details in this new version not evoking much emotional engagement. If this sequence provokes some emotional experience, it is because we attempt to emotionally tune into the events narrated and we have some resources to help us to do so. We have been presented with a scene of everyday family life, and we can understand the events narratively through our ability to understand what family life means to us, and the types of meaningful interactions that are likely to occur. Registering meaningful interactions, I take it, emerges with an emotional cadence, because an emotional cadence co-emerges with a sense of how things are related through time.

Adding random details to a sequence of events does not make such a sequence more narratively understood: Alysha scratched her nose with her index finger; later, for tea, she had rice and peas; at the same time, Douglas the neighbour came home from work; and later, the neighbour on the other side listened to the news on Radio Four. There is detail here, but the emotional intensity is minimal. We don't experience this sequence particularly narratively because the details are confusing. Maybe it conjures up some sense of the mundane, the anonymity of modern life. If it does, it is because we search for meaningful connections in spite of a random but detailed chain of events, rather than because it is details, instead of an emotional cadence, that make a sequence of events narrative.

I think these illustrations help to support the notion that an emotional cadence is constitutive of narrative engagement: our narrative sense comes about through emotionally connecting parts of a sequence together. In this way, an emotional cadence is necessary for narrative understanding.

We have arrived at a richer account of narrative understanding with the intention of seeing whether this helps us understand its relationship to agency. Following Velleman, understanding a narrative involves emotionally understanding a sequence of events, which we can also understand as a perspectival view on events. However, another feature I have made explicit is the recombinable aspect of this type of understanding: we can make new sequences of events through combining various elements, where only some sequences will make sense.

\footnotetext{
$\overline{6}$ Thanks to an anonymous reviewer for prompting me to consider this objection.
} 


\section{Mental time travel as narrative understanding}

\subsection{Reconciling theories}

Galen Strawson has argued that traditional narrative theories of self have problems. He suggests that many people have selves without engaging in (what he calls) Narrativity, and that Narrativity may distort, rather that help construct, selves. But now we have been given reason to doubt that narrative understanding is best understood in the terms that Strawson understands it: it need not involve diachronicity, in the sense of explicitly referring to one's life as a whole. What I want to explain now is why we should see mental time travel as a type of narrative understanding, and why both are linked to agency regardless of whether a narrative is about our life or involves metarepresentation.

The first thing to note is the simple structural similarity. Suddendorf \& Corrabalis proposed that mental time travel involves the putting together of parts in a languagelike way. So mental time travel can produce novel scenarios. Similarly, narrative understanding, as I have described it, requires a recombinable system, one that enables parts to hang together. I hope this is a simple observation. Both mental time travel and narrative understanding involve sequencing information into patterns that can be put together in various ways.

However, what I think is most illuminating about Velleman's explanation of the experiential quality of narrative understanding is that it gives us an explanation of what it means for mental time travel to be 'inhabited' or 'indexical'. In my discussion of narrative understanding, I suggested that an emotional cadence could co-emerge with the perspectival character of narrative understanding. There is a sense, then, of both narrative understanding and mental time travel being inhabited - in both we experience ourselves as witnessing events that are not currently occurring.

What I want to suggest is that we can also understand the experience of inhabiting our own past and possible future as co-emerging with an emotional cadence. This emotional cadence, like in narrative understanding, is what enables us to have a perspective on non-occurrent events when we mentally time travel. And this perspective in mental time travel, because it is affective, is also embodied, if we understand emotions as Velleman does. Such an emotional understanding can occur pre-reflectively, but the claim is that, unlike in other types of narrative understanding, when we mentally time travel we generally do explicitly understand that we are in the story.

However, Gerrans \& Kennett have described mental time travel as an essentially indexical process, in that it is experienced as involving our selves, and it is not clear how this relates to narrative understanding. It seems to me that both are implicitly indexical through their embodied nature. Because our bodily sense of our situation is an implicit way for what is being pointed at, and what is doing the pointing, to coincide. Implicit in our affective bodily responses to a virtual situation is the experience of a self as related to that situation. So emotions, without having to represent our selves explicitly, implicitly make selves felt and tell us something about what that self is, that is, how it stands in relation to its current or virtual predicament. It is our felt affective body that is both being pointed at and doing the pointing. So to say that emotions co-emerge with perspective is a way of saying that emotion occurs with a lived indexical experience. The perspectival nature of both mental time travel and narrative understanding is another way of expressing that the indexicality of both involves a sense of self. 
Further, this phenomenology can also illuminate the role of narrative understanding and mental time travel in action. Once we view emotion as embodied and perspectival, as disclosing a sense of our relationship to the world, it is also natural to recognise that it contains a sense of certain actions becoming (more) available (Prinz 2004; Slaby 2012). Through this, we can see how the indexicality of narrative understanding is both experiential and action-guiding.

Our sense of how the world is bearing on us is also a sense of how we could interact with it. If what it means for emotions to be embodied is that they are "proprioceptive and kinaesthetic", or an even broader set of bodily reactions (Prinz 2004; Damasio 1999), then the experience of them is linked to action preparedness. Such bodily reactions emerge with our bodies anticipating what types of actions would enable a creature to best deal with a situation. On this view, emotions emerge with certain possible actions gaining prominence, and others receding. For example, fear, when experienced, also emerges with fleeing, fighting or freezing becoming (more) available to us. This doesn't mean that we take up these actions in all cases, but that there is some urge to (Prinz 2004, p. 193). Set back into the context of narrative understanding, the emotionality and embodiment of narrative understanding is also a preparation for action.

We can add this bit of our puzzle to the explanation of how narrative understanding and mental time travel are involved in action. As we learn, through narrative understanding, what events mean to us, we also learn how to act on them. And so, as we encounter events in life, our capacity to embed them in a narrative is the awareness of how we can act on them.

On this proposal, mental time travel is a particular type of narrative understanding. It is narrative understanding where we explicitly identify one of the characters in the narrative as our selves. Yet a sense of self is always present in narrative understanding because both involve having an embodied perspective on a sequence of events. And we can give the same explanation for the phenomenology in both cases: during both we experience an emotional cadence so that we have an embodied sense of how the events in the narrative relate to us.

When seen this way, it is not clear, on a theoretical level, that consideration of our selves and our lives should be crucial in narrative theories of agency.

\subsection{Narrative understanding \& diachronic agency}

But now it seems like there is a tension in my view. On the one hand, I have responded to Strawson's concern with Narrativity by arguing that narrative understanding may not be diachronic, if by diachronicity we mean giving an explicit narrative of our own life. On the other, I've argued that mental time travel is a version of narrative understanding. Yet it seems that mental time travel contributes to our agency in virtue of it giving us an experiential understanding of our own lives, which we recognise as such. Can we uphold Strawson's observation that diachronicity isn't fundamental to human agency, while giving an account of how mental time travel contributes to agency? I think we can if we recognise the different ways that narrative understanding can contribute to agency.

Here's a way that we might act on the future based on our capacity for mental time travel. I think about my future and decide that getting through another Edinburgh winter will be arduous, and that I ought to focus on finishing my $\mathrm{PhD}$; then, bringing this image to mind when I feel like sleeping in might help motivate me to roll out of bed. The imagined feeling of winter-fatigue, wrapped up in its narrative context, comes with actions that contribute to avoiding that dreaded fate. 
Equally, we can get the same affect using narrative understanding more broadly. Remembering a documentary about the lives of refugees might contribute to Sally's desire to donate money to a friend going to volunteer at Dunkirk, because of the emotional cadence that accompanies her understanding of the situation. Sally need not be thinking about herself or her life to experience sadness and to connect that to a chain of events that maybe can be slightly ameliorated if she acts a certain way. And this action of donating is motivated by her narrative understanding of events. Perhaps this narrative understanding includes a sense of injustice and sadness that is captured by the whole narrative, and maybe a sense of hope about how the narrative might continue if more money is provided to the refugees. Further, this action can be motivated by these emotions without Sally reflecting on how she feels. The donating of money feels right in this context given her understanding of the narratives told about refugees.

In this case, Sally need not even be explicitly representing people's mental states or feelings. While Sally might empathise with the refugees, all her explicit description of events need include, for example, is that they are fleeing war, coming to a new country, where their living conditions are precarious and impoverished, and they are cut off from their family and/or their normal social network. While she might be taking the perspective of others while understanding the narrative, she need not be thinking of that perspective as a perspective.

Narrative understanding contributes to agency here because it gives Sally a relatively unified perspective on events, and so this type of understanding comes together with Sally seeing only particular actions as making sense. ${ }^{7}$ Narrative understanding enables the type of agency where some actions, rather than others, are rational in light of our perspective. In this case, a perspective that is not explicitly concerned with our selves but is a coherent perspective of events in the world.

There is a concern that acting on such a narrative understanding of events cannot equate to an act of agency because there is no self that has authorship of the story. Sally could be swayed in another direction as soon as she gets told another story, maybe about how refugees are being housed before British citizens.

What makes it possible to call Sally's behaviour 'acting for reasons', however, is that she can reflect on the stories she tells and change her narrative understanding. She can investigate whether refugees are housed before British citizens, and she can think about the lives of different people and what changes to them mean. If she does so, she isn't necessarily reflecting on her life, and, in the sense in which I'm using it, this reflection need not be metarepresentational. Sally is reflecting on her beliefs about world, but she isn't reflecting on her beliefs as beliefs. As far as she is concerned, she is reflecting on how the world is.

I propose that we should see narrative understanding as making agency possible because, while we can understand narratives implicitly, that is, before we reflect on them, it is also possible to reflect on our narrative understanding and change our understanding through reflection. ${ }^{8}$ This makes agency possible, because such reflective capacities make it possible for us to be the originators of the perspectives that we act on and through (see Taylor 1985).

\footnotetext{
${ }^{7}$ See Davenport (2012), who similarly argues that narrative understanding is required to provide the kind of unity that allows us to be autonomous creatures.

${ }^{8}$ See also Schechtman (1996), who introduces an 'articulation constraint': for something to be a narrative it is necessary that we could articulate the story if we wanted to, even if our current understanding of it has not yet been articulated.
} 
However, there are limitations of this type of narrative understanding where there is no representation of the self. While narrative understanding with no explicit awareness of self may help us act in our present situation on factors that are not currently before us, it doesn't necessarily help us to engage in long-term planning, or to act on those plans in the future. To make plans, we need to have some sense of an entity that exists through time, something that can act in the future. We seem to need the idea of a creature that has spatio-temporal continuity, and which we understand to be identical to the creature we currently are. When the future comes to pass, we also need to identify as that creature from which certain behaviours are expected at certain points in time. It is through this understanding that a creature can execute the actions that enable a longterm plan to come to fruition.

So I want to suggest there is a type of narrative understanding where we are reflectively aware of our self, but we do not explicitly understand this self as a thinking thing. That is, we can have a non-metarepresentational understanding of our selves. Rather, self is represented in terms of its behaviour, roles and responsibilities (Bloch 2011). So, for instance, if Sally plans to volunteer in Dunkirk with refugees, she needs to be able to understand herself as a thing that exists through time and can behave in certain ways in the future. Once she has made her plans, to execute them she needs to see herself as the creature who ought to do certain things at certain times to carry out a task. Whether planning like this could use mental time travel will depend on whether we think metarepresentation is an essential part of mental time travel. We saw earlier that many seem to take for granted that mental time travel is metarepresentational, but it doesn't seem to me that this connection is one of necessity. If we go with my inclination, and suggest this type of planning involves mental time travel, then it augments what we take to characterise agency: it turns out that a mental time travel account of planning agency does not commit us to saying that metarepresentation is necessary for planning.

In contrast, Bratman (2000) clearly does take metarepresentation to be central to agency: we are "reflective about our motivations" and this is "among the core features of human agency" (p. 35). Velleman is less clear on the matter and admits as much in 2007. Here he reports that he has been oscillating between two different accounts of the self-understanding involved in agency. One involves thinking about one's own psychology, and is thus metarepresentational, and the other is narrative self-understanding, which isn't obviously metarepresentational. So there is a tradition of thinking of the capacities required for agency as metarepresentational, although, as we see with Velleman, a narrative view of agency does not require us to see metarepresentation as crucial.

Furthermore, highlighting a middle way - between an implicit sense of self and a metarepresentational self - allows us to see that planning could contribute towards agency without necessarily leading to any of the distortion that Strawson is worried about. Imagining oneself through time to plan doesn't require the metarepresentational autobiography that Strawson thinks will lead to distortions. If planning, and the execution of plans, involves understanding a chain of events through an emotional cadence, it would, on my account, be an exercise of our narrative capacities. I'll leave it to the reader to make their own assessment concerning whether it is plausible that there are many people who rarely plan through imagining their selves through time, as Strawson suggests. 
A last note to make on types of narrative understanding is that I'm not claiming that metarepresentational narratives don't enhance our agency, and aren't special in some ways. For example, we need metarepresentation when we make decisions about what to do based on our understanding of the values we care about, or when we want to think about how our psychology might be different in the future (Vierkant and Paraskevaides 2012). After a whole day dealing with a toddler in a particularly obstreperous mood, it's important that Dean's rage is accompanied with the knowledge of his views about childcare. Instead of shouting, he reminds himself to breathe and take some time out before acting. Making good decisions when feeling strong emotions or being intoxicated may be facilitated by explicit knowledge about our own psychology. The claim, however, is that this particular type of reflection is not essential to all acts of agency.

Once we distinguish between ways that the self can be present in these activities, we can explain why different types of narrative understanding can contribute in different ways to agency. Thus, the view I presented here furthers current thought in this area in two ways. The first is through unifying accounts, by explaining how diachronic agency can be understood as being underpinned by narrative understanding. The second is to distinguish between ways that the self can be present in our narrative understanding, enabling us to distinguish between types of narrative understanding. Narrative understanding can engage just our pre-reflective sense of self, or it can engage an explicit understanding of self that may, or may not be, metarepresentational. ${ }^{9}$

Each of these possibilities comes with distinct functional profiles in the sense that they contribute to our agency in different ways. Narrative understanding with a purely implicit self enables us to act in a present that is framed by a narrative context of possible causes and consequences. Understanding explicit narratives about our selves helps us to plan and act on plans, while metarepresentational narrative understanding enables us to act on what we understand to be our values, despite our current state.

With these distinctions, we also gain a new possible explanation of the problems that people with vmPFC damage have with making and acting on decisions. We can agree with Gerrans \& Kennett that they have a problem with an indexical mode of thinking but suggest that this reflects a problem with narrative understanding in general, rather than a particular deficit in mental time travel. On this view, the reports given by people with vmPFC concerning their inability to mental time travel is just a symptom of a wider issue. The general issue is an inability to put their current situation into a narrative context, one that may not explicitly be about their lives or their representational processes. This narrative context is affective and embodied and expresses an action-orientated sense of what matters.

Therefore we have a competing explanation of why people with vmPFC lesions have problems making and acting on decisions. On this account, the vmPFC is involved in narrative understanding, which contributes to our ability to make and act on decisions. It is hard to read the empirical evidence as determining one view or the other. I am not aware of studies that make this distinction between ways in which the self might be present in narrative understanding or mental time travel. Therefore, the theory presented here illustrates the need for further research, where what is investigated is the relationship between the vmPFC and the different ways that we can experience self while understanding narratives.

\footnotetext{
${ }^{9}$ See also Schechtman (1996) who presents narrative understanding of our lives as generally implicit, but constitutive of our identity.
} 
Both mental time travel and narrative understanding have been put forward as processes that enable us to make decisions and act on them. What I have highlighted here is that we can understand how both can contribute to making decisions and acting on them by thinking through what narrative understanding entails. Then, we can see how mental time travel is a particular genre of narrative understanding. Note that this lets us make the same strong claim that Velleman makes - that the ability to understand narratives is crucial for action - while side-stepping Strawson's critique of narrative theories of human psychology. It is its emotional nature that enables narrative understanding to be linked with action. And, on this view, narrative understanding is an important psychological process because it allows us to inhabit a sequence of events without it requiring us to think about our lives as a whole. So we can argue that narrative understanding is a general part of human psychology without claiming it has the features that Strawson thinks of as specific to only some people.

\section{Conclusion}

This paper has been concerned with bringing together two debates, about mental time travel and narrative understanding, which have many overlaps, but whose precise relationship has not been mapped. I have argued that mental time travel should be seen as a type of narrative understanding where one of the characters in the narrative is explicitly thought to be ones self. Mental time travel is generally thought of as a metarepresentational capacity, one where one represents ones representational states. However, I have claimed that explicitly thinking about our selves, our lives, and our representational capacities are not necessary to narrative understanding, or to the relationship between narrative understanding and agency.

Open Access This article is distributed under the terms of the Creative Commons Attribution 4.0 International License (http://creativecommons.org/licenses/by/4.0/), which permits unrestricted use, distribution, and reproduction in any medium, provided you give appropriate credit to the original author(s) and the source, provide a link to the Creative Commons license, and indicate if changes were made.

\section{References}

Ahmed, S. (2004). The cultural politics of emotion. Edinburgh: Edinburgh University Press.

Atkins, K. (2008). Narrative identity and embodied continuity. In K. Atkins \& C. Mackenzie (Eds.), Practical identity and narrative agency (pp. 78-98). Abingdon: Routledge.

Bloch, M. (2011). The blob. Anthropology of this Century, 1. http://aotcpress.com/articles/blob/ http://aotcpress.com/archive/issue-1/.

Botzung, A., Denkova, E., \& Manning, L. (2008). Experiencing past and future personal events: functional neuroimaging evidence on the neural bases of mental time travel. Brain and Cognition, 66(2), 202-212.

Bratman, M. E. (2000). Reflection, planning, and temporally extended agency. The Philosophical Review, $109(1), 35-61$.

Damasio, A. R. (1999). The feeling of what happens: body and emotion in the making of consciousness. Boston: Houghton Mifflin Harcourt.

Davenport, J. J. (2012). Narrative identity, autonomy, and mortality: from Frankfurt and MacIntyre to Kierkegaard. Abingdon: Routledge.

Debus, D. (2007). Being emotional about the past: on the nature and role of past-directed emotions. Noûs, 41(4), 758-779.

Debus, D. (2013). Thinking about the past and experiencing the past. Mind \& Language, 28(1), 20-54. 
Debus, D. (2014). 'Mental time travel': remembering the past, imagining the future, and the particularity of events. Review of Philosophy and Psychology, 5(3), 333-350.

Dennett, D. C. (1989). The origins of selves. Cogito, 3(3), 163-173.

Dennett, D. C. (1992). The self as a center of narrative gravity. In Self and consciousness: Multiple perspectives. Hillsdale: Erlbaum.

Gerrans, P., \& Kennett, J. (2010). Neurosentimentalism and moral agency. Mind, 119(475), 585-614.

Gerrans, P., \& Kennett, J. (2017). Mental time travel, dynamic evaluation, and moral agency. Mind, 126(501), 259-268.

Goldie, P. (2012). The mess inside: narrative, emotion, and the mind. Oxford: Oxford University Press.

Kennett, J., \& Matthews, M. (2008). Normative agency. In Practical Identity and Narrative Agency Ed. Atkins, K., \& Mackenzie, C., (pp. 212-231) New York: Routledge.

Korsgaard, C. M. (1989). Personal identity and the unity of agency: a Kantian response to Parfit. Philosophy \& Public Affairs, 18, 101-132.

Kwan, D., Craver, C. F., Green, L., Myerson, J., Boyer, P., \& Rosenbaum, R. S. (2012). Future decisionmaking without episodic mental time travel. Hippocampus, 22(6), 1215-1219.

Markowitsch, H. J., \& Staniloiu, A. (2011). Memory, autonoetic consciousness, and the self. Consciousness and Cognition, 20(1), 16-39.

Prinz, J. J. (2004). Gut reactions: a perceptual theory of emotion. Oxford: Oxford University Press.

Ricoeur, P. (1980). Narrative time. Critical Inquiry, 7(1), 169-190.

Rudd, A. (2009). In defence of narrative. European Journal of Philosophy, 17(1), 60-75.

Schechtman, M. (1996). The constitution of selves. Ithaca: Cornell University Press.

Schechtman, M. (2007). Stories, lives, and basic survival: a refinement and defense of the narrative view. Royal Institute of Philosophy Supplement, 60, 155-178.

Slaby, J. (2012). Affective self-construal and the sense of ability. Emotion Review, 4(2), 151-156.

Strawson, G. (2004). Against narrativity. Ratio, 17(4), 428-452.

Suddendorf, T., \& Corballis, M. C. (2007). The evolution of foresight: what is mental time travel, and is it unique to humans? Behavioral and Brain Sciences, 30(03), 299-313.

Szpunar, K. K., Watson, J. M., \& McDermott, K. B. (2007). Neural substrates of envisioning the future. Proceedings of the National Academy of Sciences, 104(2), 642-647.

Taylor, C. (1985). Self-interpreting animals. In Human agency and language: Philosophical papers 1, (pp. 45-76). Cambridge: Cambridge University Press.

Velleman, J. D. (1992). What happens when someone acts? Mind, 101(403), 461-481.

Velleman, J. D. (2003). Narrative explanation. The Philosophical Review, 112(1), 1-25.

Velleman, J. D. (2005). The self as narrator. In Self to self: selected essays. New York: Cambridge University Press.

Velleman, J. D. (2007). Reply to Catriona Mackenzie. Philosophical Explorations, 10(3), 283-290.

Viard, A., Chételat, G., Lebreton, K., Desgranges, B., Landeau, B., de La Sayette, V., \& Piolino, P. (2011). Mental time travel into the past and the future in healthy aged adults: an fMRI study. Brain and Cognition, 75(1), 1-9.

Vierkant, T., \& Paraskevaides, A. (2012). Mindshaping and the intentional control of the mind. Consciousness in Interaction: The Role of the Natural and Social Context in Shaping Consciousness, 86, 107.

Wheeler, M. A., Stuss, D. T., \& Tulving, E. (1997). Toward a theory of episodic memory: the frontal lobes and autonoetic consciousness. Psychological Bulletin, 121(3), 331. 